\title{
CULTIVOS INTERCALARES E CONTROLE DE PLANTAS DANINHAS EM PLANTIOS DE MARACUJÁ-AMARELO ${ }^{1}$
}

\author{
ADELISE DE ALMEIDA LIMA², RANULFO CORRÊA CALDAS ${ }^{2}$, ANA LÚCIA BORGES ${ }^{3}$, CECÍLIA HELENA SILVINO \\ PRATA RITZINGER ${ }^{4}$, ALDO VILAR TRINDADE ${ }^{3}$, MÔNICA DE MOURA PIRES ${ }^{5}$, MOEMA MARIA BADORÓ \\ CARTIBANI MIDLEJ ${ }^{6}$, HENRIQUE TOMÉ DA COSTA MATA ${ }^{7}$, JOSÉ DA SILVA SOUZA ${ }^{2}$
}

\begin{abstract}
Resumo - Objetivou-se identificar cultivos intercalares e métodos integrados de controle de plantas daninhas em maracujá-amarelo (Passiflora edulis Sims f. flavicarpa Deg.) como fatores que viabilizem a sua produção e rentabilidade. O experimento foi instalado em maio de 1999 , conduzido em espaldeira vertical com um fio de arame a 2,0m do solo, no espaçamento de 2,5m x 5,0m, em blocos casualizados, com seis tratamentos e quatro repetições, sendo T1: milho (Zea mays L. - BR 106) como cultura intercalar; T2: feijão (Phaseolus vulgaris L. - cultivar Pérola) como cultura intercalar; T3: feijão-de-porco nas entrelinhas e capina com enxada nas linhas; T4: feijão-de-porco nas entrelinhas e controle químico nas linhas (glifosate a 1,5 $\mathrm{kg} / \mathrm{ha}$ ); T5: planta daninha controlada quimicamente (em toda a parcela com alachlor a 2,8 kg/ha + diuron a 1,2 kg/ha em pré-emergência e glifosate a 1,5 kg/ha em pós-emergência); e T6: testemunha (capina com enxada em área total). Os dados analisados, no período de produção (maio de 1999 a abril de 2000), mostraram que não houve diferenças estatísticas entre os tratamentos para produtividade (indústria), peso médio, comprimento e diâmetro dos frutos, sólidos solúveis totais e acidez. Contudo, houve significância para produtividade total e in natura, com destaque para a utilização do feijão como cultura intercalar, com produtividade do maracujazeiro de 12,82 t/ha. Tanto o milho como o feijão podem ser recomendados como culturas intercalares no primeiro ano de cultivo do maracujá-amarelo. Os herbicidas aplicados em pré e pós-emergência foram economicamente viáveis e não mostraram efeito tóxico sobre as plantas de maracujá-amarelo.
\end{abstract}

Termos para indexação: Passiflora edulis Sims f. flavicarpa Deg., controle químico, cultura intercalar.

\section{INTERCROPPING AND WEED CONTROL IN YELLOW PASSION FRUIT ORCHARD}

ABSTRACT - This work aimed identifying crops for intercropping and integrated methods for weed control in yellow passion fruit (Passiflora edulis Sims f. flavicarpa Deg.) orchard, that will favor its production and profitability. The experiment was set up in May 1999, with the plants being conducted by a vertical support structure with one wire extended $2.0 \mathrm{~m}$ above the soil surface, and distributed in a spacing of $2.5 \mathrm{~m} \times 5.0 \mathrm{~m}$. The experimental design was in randomized blocks, with four replications and six treatments as follows: T1 - maize (Zea mays L. , cv. BR 106) as intercrop; T2 - bean (Phaseolus vulgaris L., cv. Pérola) as intercrop; T3 - pork bean (Canavalia ensiformis L.) in the interspace and hoeing in the plant lines; $\mathrm{T} 4$ - pork bean in the interspace and chemical weed control in the plant lines (glyphosate at $1.5 \mathrm{~kg} . / \mathrm{ha}$ ); $\mathrm{T} 5$ - general chemical weed control (alachlor at $2.8 \mathrm{~kg} / \mathrm{ha}$ + diuron at $1.2 \mathrm{~kg} / \mathrm{ha}$ in pre-emergence and glyphosate at $1.5 \mathrm{~kg} / \mathrm{ha}$ in post-emergence); T6 - control (general hoeing). Data obtained during the harvest period (May 1999 to April 2000) showed no statistical differences among treatments for yield (industry), fruit weight, length and diameter, total soluble solids and total titrable acidity. However, there was a statistical significance for total yield and yield for the fresh fruit market, with best results for bean as intercrop, giving a passion fruit yield of $12.82 \mathrm{t} / \mathrm{ha}$. Both bean and maize should be recommended as intercrops during the first year of passion fruit cycle. The herbicides used both in pre- and post-emergence were economically viable and did not show toxic effects on the yellow passion fruit plants.

Index terms: Passiflora edulis Sims f. flavicarpa Deg., chemical control, intercrops.

\section{INTRODUAÇÃO}

A cultura do maracujá-amarelo (Passiflora edulis Sims f. flavicarpa Deg.) enfrenta uma série de problemas de natureza técnica, que contribuem para reduzir a margem de lucro dos produtores. Dentre as alternativas capazes de ampliar a lucratividade e o rendimento da cultura, destacam-se a utilização de cultivos intercalares e os métodos integrados no controle de plantas daninhas, práticas que apresentam uma série de vantagens sob os pontos de vista técnico e econômico.

Não foram encontrados trabalhos sobre o uso de culturas intercalares e métodos integrados de controle de plantas daninhas na cultura do maracujazeiro. As poucas informações existentes são oriundas de observações empíricas, sem metodologia científica, portanto, sem embasamento técnico.

De acordo com Leihner (1983), a maior estabilidade que apresentam os sistemas intercalares na produção de cultivos alimentares, é de fundamental importância para o pequeno produtor, uma vez que lhe assegura o sustento e diminui o risco da perda total nas suas colheitas. O uso de culturas intercalares em pomares é uma prática típica de pequenas propriedades. Esse cultivo simultâneo de duas ou mais culturas, além de assegurar uma subsistência mais estável em termo de renda e alimento, permite minimizar os riscos decorrentes do monocultivo (Coelho et al., 1994).

Poucos são os métodos utilizados para elevar a produção de alimentos, e a solução mais viável é optar pelo uso mais intensivo da terra durante o mesmo ano agrícola, utilizando sistemas de plantios consorciados (Mattos \& Souza 1987).

A utilização das leguminosas feijão-de-porco e soja perene e/ ou feijão vigna, como adubo verde complementar e/ou como alternativa para a adubação mineral de citros, provocou competição com a planta cítrica e levou à redução do diâmetro do tronco, altura das plantas, circunferência da copa, percentagem de suco, altura, diâmetro e espessura da casca do fruto; entretanto, características do solo, como $\mathrm{pH}$, CTC, saturação em bases, matéria orgânica e microporosidade, foram aumentadas, bem como a acidez total e brix (Magalhães, 1994).

No estudo realizado por Barbosa (1994), sobre métodos integrados de controle de plantas daninhas em abacaxizeiro, associando-se à capina manual, o uso de herbicidas ou de tração animal evidenciou a maior eficiência e economicidade do tratamento herbicida + capina manual em relação aos demais tratamentos, com maior relação benefício/ custo.

De modo geral, os herbicidas aplicados na cultura do maracuja-

\footnotetext{
1 (Trabalho 037/2002). Recebido: 09/03/2002. Aceito para publicação: 26/09/2002.

2 Eng $^{\circ}$ Agr $^{\circ}$, MSc. Pesquisador da Embrapa Mandioca e Fruticultura, Caixa Postal 007, CEP 44.380-000, Cruz das Almas, Bahia, adelise@ cnpmf.embrapa.br

3 Eng $^{\circ}$ Agr $^{\circ}$, DSc. Pesquisador da Embrapa Mandioca e Fruticultura, analucia @ cnpmf.embrapa.br

4 Eng ${ }^{\circ}$ Agr ${ }^{\circ}$, PhD. Pesquisador da Embrapa Mandioca e Fruticultura, cecilia@ cnpmf.embrapa.br

5 Prof $^{\circ}$.Adjunto, DSc. do Departamento de Ciências-Econômicas da Universidade Estadual de Santa Cruz- UESC. Rodovia Ilhéus/Itabuna km 16, CEP 45650-000,

Ilhéus, Bahia, mpires@uesc.br

6 Profo.Adjunto, MSc. do Departamento de Ciências-Econômicas da UESC, moema@uesc.br

7 Prof $^{\circ}$.Visitante, DSc. do Departamento de Ciências-Econômicas da UESC
} 
zeiro em pré-emergência, com bons resultados, são o diuron, o bromacil e o DCPA. Todos apresentam seletividade toponômica em relação à cultura, ou seja, permanecem na camada superficial do solo sem atingir um grande volume de raízes e, conseqüentemente, com pequena absorção e translocação pela planta (Durigan 1987).

Segundo Silva \& Rabelo (1991), os produtores têm usado o Gramoxone ${ }^{\circledR}$ ou Roundup®, em alguns plantios de maracujazeiro do Triângulo Mineiro e de São Paulo, na dose de 1,5 a 2,0 1/ha, em aplicações dirigidas nas entrelinhas, para manter a cobertura morta.

Lima et al. (1999), verificando a seletividade dos herbicidas aplicados em pré-emergêcia diuron, oxyfluorfen, alachlor e atrazine+metolachlor, em mudas de maracujá-amarelo, constataram que apenas atrazine+metolachlor, nas doses de 6,0 e 12,0 kg/ha, causou efeito adverso (forte injúria) às mudas, enquanto os demais se mostraram promissores para utilização em campo.

Objetivou-se, nesse trabalho, identificar culturas intercalares e métodos integrados de controle de plantas daninhas para o maracujáamarelo como fatores que viabilizem sua produção e rentabilidade, com maiores retornos para os produtores.

\section{MATERIALEMÉTODOS}

O experimento foi realizado no período de maio de 1999 a abril de 2000, utilizando-se do maracujá-amarelo, conduzido em espaldeira vertical com um fio de arame a 2,0 m do solo, no espaçamento de $2,5 \mathrm{~m}$ x 5,0m. A área experimental estava situada na Escola de Agronomia da Universidade Federal da Bahia, Município de Cruz de Almas-BA, situado no Recôncavo baiano, que apresenta altitude de 220 metros acima do nível do mar, índices médios anuais de $24,7{ }^{\circ} \mathrm{C}$ de temperatura, precipitação anual média de $1.240 \mathrm{~mm}$ e umidade relativa do ar média anual de $80 \%$. O solo é franco argilo-arenoso, relevo plano, com as seguintes características químicas na camada de 0 a 20cm: $\mathrm{pH}$ em água $=5,0 ; \mathrm{P}($ Mehlich $) 2,0 \mathrm{mg}$ $\mathrm{dm}^{-3} ; \mathrm{K}^{+1}$ (Mehlich) $73,0 \mathrm{mg} \mathrm{dm}^{-3} ; \mathrm{Ca}^{+2}=1,0 \mathrm{cmmol} \mathrm{dm}^{-3} ; \mathrm{Mg}^{+2}=0,6 \mathrm{cmmol}$ $\mathrm{dm}^{-3} ; \mathrm{Na}^{+1}=0,05 \mathrm{cmmol}_{\mathrm{dm}}^{-3} ; \mathrm{Al}=0,3 \mathrm{cmmol}_{\mathrm{cm}} \mathrm{dm}^{-3} ; \mathrm{S}=1,84 \mathrm{cmmol}_{\mathrm{c}} \mathrm{dm}^{-3}$; $\mathrm{CTC}=4,48 \mathrm{cmmol}_{\mathrm{c}} \mathrm{dm}^{-3} ; \mathrm{V}=41 \% ; \mathrm{e} \mathrm{MO}=11,6 \mathrm{~g} \mathrm{~kg}^{-1}$.

Foi utilizado o delineamento experimental de blocos casualizados, com seis tratamentos e quatro repetições, sendo T1: milho (Zea mays L. - BR 106) como cultura intercalar; T2: feijão (Phaseolus vulgaris L. - cultivar Pérola) como cultura intercalar; T3: feijão-de-porco nas entrelinhas e capina com enxada nas linhas; T4: feijão-de-porco nas entrelinhas e controle químico nas linhas (glifosate a 1,5 kg/ha); T5: planta daninha controlada quimicamente na área total com alachlor a 2,8 $\mathrm{kg} / \mathrm{ha}+$ diuron a $1,2 \mathrm{~kg} / \mathrm{ha}$ em pré-emergência e glifosate a $1,5 \mathrm{~kg} / \mathrm{ha}$ em pós-emergência; e T6: testemunha (capina com enxada em área total). A parcela experimental constou de cinco plantas em $62,5 \mathrm{~m}^{2}$, enquanto a parcela total, de 14 plantas em $175 \mathrm{~m}^{2}$.

O milho foi semeado em linhas espaçadas de 1,0 m entre si e a $0,75 \mathrm{~m}$ da linha do maracujazeiro. Dentro da linha, foram plantadas duas sementes por cova espaçadas de $0,40 \mathrm{~m}$. O feijão foi semeado em linhas espaçadas de $0,5 \mathrm{~m}$ entre si e a $0,75 \mathrm{~m}$ da linha do maracujazeiro. Dentro da linha, foram plantadas duas sementes por cova, espaçadas de $0,20 \mathrm{~m}$. $\mathrm{O}$ feijão-de-porco foi semeado a lanço a 1,00 $\mathrm{m}$ da linha do maracujazeiro.

Os tratos culturais (capina manual e controle de pragas e doenças) e a adubação (cova e cobertura) foram utilizados para cada cultura intercalar.

No tratamento T5, os herbicidas em pré-emergência, alachlor a $2,8 \mathrm{~kg} / \mathrm{ha}$ + diuron a $1,2 \mathrm{~kg}$./ha, foram aplicados com um pulverizador costal, equipado com bico Teejet 110.03 e consumo de calda de 285 litros/ha. A aplicação do herbicida em pré-emergência foi realizada logo após o transplantio das mudas, em maio de 1999, e em pós-emergência, glifosate a $1,5 \mathrm{~kg} / \mathrm{ha}$ foi aplicado com um pulverizador costal, equipado com bico Teejet 110.03 e consumo de calda de 228 litros/ha. A infestação era de 30 a 40\% de plantas daninhas nas parcelas, em setembro de 1999. A testemunha, com controle realizado por capina manual (enxada), seguiu o mesmo critério (capina com infestação de $30-40 \%$ de plantas daninhas nas parcelas).
A eficiência de controle dos herbicidas sobre as plantas daninhas foi avaliada visualmente por três observadores, e utilizada a média para análise dos resultados. Foram feitas aos 45 e 90 dias após a aplicação, utilizando-se da escala de Frans \& Talbert (1977). A ação dos herbicidas sobre as plantas de maracujá foi avaliada por meio do vigor expresso pelo diâmetro do caule a $20 \mathrm{~cm}$ do solo, aos 90, 180 e 270 dias após o plantio.

A calagem realizada antes do plantio e as adubações seguiram as recomendações da Comissão Estadual de Fertilidade do Solo (1989).

As seguintes variáveis foram avaliadas durante o período de maio de 1999 a abril de 2000: produtividade total, produtividade ("in natura" e para a indústria), peso médio e tamanho (altura e diâmetro) de frutos, sólidos solúveis totais, acidez, rendimento em suco e relação sólidos solúveis totais/acidez. As colheitas dos frutos foram realizadas três vezes por semana $\left(2^{\mathrm{a}}, 4^{\mathrm{a}}\right.$ e $6^{\mathrm{a}}$ feira). Para a avaliação dos caracteres físicos e químicos foram utilizados 10 frutos por tratamento, no mês de janeiro, considerado o mais quente do ano.

As plantas daninhas mais freqüentes na área experimental durante a aplicação dos herbicidas em pré e pós-emergência foram: beldroega (Portulaca oleracea L), café-bravo (Croton lobatus L.), poaiabranca (Richardia brasiliensis Gomez.) e capim-açu (Digitaria insularis (L.)Mea ex Ekman).

Os dados foram submetidos à análise de variância (teste $\mathrm{F}$ ) e as médias dos tratamentos comparadas pelo teste de Tukey, a 5\% de probabilidade.

\section{RESULTADOSEDISCUSSÃO}

A mistura de diuron a 1,2 kg/ha + alachlor a $2,8 \mathrm{~kg} / \mathrm{ha}$ aplicada em pré-emergência não mostrou efeito fitotóxico sobre as plantas de maracujá-amarelo, por ocasião das avaliações visuais, realizadas aos 45 e 90 dias após a aplicação da mistura dos herbicidas. Os valores encontrados foram de 0\%, que, segundo Frans Talbert (1977), são sem efeito, ou seja, sem dano ou injúria da cultura. Também os valores encontrados para diâmetro do caule mostraram que o controle químico das plantas invasoras não promoveu desenvolvimento diferenciado das plantas de maracujazeiro, uma vez que não houve diferença significativa entre o tratamento químico e os demais tratamentos (Tabela 1). No trabalho realizado com herbicida, aplicado em pré-emergência x pós-emergência em viveiro de seringueira, Lima (1994) obteve também a não-ocorrência de efeito tóxico sobre as plântulas enviveiradas. Resultados semelhantes foram obtidos por Pereira, em 1987, com o herbicida imazypar, não apresentando efeitos fitotóxicos aparentes às plantas da seringueira. Por outro lado, os valores encontrados de $69 \%$ e $53 \%$ para 45 e 90 dias, respectivamente, com a mistura em pré-emergência para o controle das plantas daninhas, indicam efeito deficiente a moderado. Assim, doses maiores para os herbicidas aplicados em pré-emergência devem ser testadas para conseguir-se controle eficiente e mais prolongado de plantas daninhas. A aplicação sucessiva de um herbicida em pós-emergência, após um aplicado em pré-emergência, pode proporcionar controle mais eficiente de plantas daninhas nessa cultura.

TABELA 1 - Diâmetro do caule de plantas de maracujazeiro, aos 90, 180 e 270 dias após a aplicação dos herbicidas em pré-emergência. Cruz das Almas-BA, 1999-2000.

\begin{tabular}{lccc}
\hline & \multicolumn{3}{c}{ Diâmetro do caule (cm) } \\
\cline { 2 - 4 } \multicolumn{1}{c}{ Tratamento } & 90 dias & 180 dias & 270 dias \\
\hline Milho como cultura intercalar & $0,64 \mathrm{a}$ & $1,37 \mathrm{a}$ & $1,91 \mathrm{a}$ \\
Feijão como cultura intercalar & $0,72 \mathrm{a}$ & $1,58 \mathrm{a}$ & $2,04 \mathrm{a}$ \\
Cobertura do solo com feijão-de-porco & $0,68 \mathrm{a}$ & $1,48 \mathrm{a}$ & $2,09 \mathrm{a}$ \\
Feijão-de-porco nas entrelinhas e controle químico nas linhas & $0,70 \mathrm{a}$ & $1,37 \mathrm{a}$ & $2,04 \mathrm{a}$ \\
Planta daninha controlada quimicamente (em toda parcela) & $0,77 \mathrm{a}$ & $1,62 \mathrm{a}$ & $2,14 \mathrm{a}$ \\
Testemunha (capina manual, sistema utilizado pelo produtor) & $0,73 \mathrm{a}$ & $1,54 \mathrm{a}$ & $1,99 \mathrm{a}$ \\
\hline C.V. (\%) & 9,6 & 8,7 & 10,6 \\
\hline
\end{tabular}

Médias seguidas da mesma letra, na coluna, não diferem entre si, ao nível de 5\% de probabilidade, pelo teste de Tukey. 
Observa-se, pela Tabela 2, que no período de produção, de maio de 1999 a abril de 2000, não houve diferenças estatísticas entre os tratamentos para produtividade (indústria), peso médio, comprimento e diâmetro dos frutos. Contudo, houve significância para produtividade total e in natura, com destaque para a utilização do feijão como cultura intercalar, proporcionando produtividade total para o maracujazeiro de 12,8 t/ha. Apesar de não haver diferença estatística entre os tratamentos, houve tendência de o tratamento T4 ( feijão-de-porco x controle químico) proporcionar menor produtividade total.

TABELA 2 - Produtividade total, para consumo e indústria, peso médio, comprimento e diâmetro do fruto sob cultivos intercalares e controle de plantas daninhas no primeiro ano de produção. Cruz das Almas-BA, 1999-2000.

\begin{tabular}{|c|c|c|c|c|c|c|c|c|}
\hline \multirow[b]{2}{*}{ Tratamento } & \multicolumn{5}{|c|}{ Produtividade } & \multirow[b]{2}{*}{$\begin{array}{c}\mathrm{PMF}^{2} \\
\text { (g) }\end{array}$} & \multirow[b]{2}{*}{$\begin{array}{l}\mathrm{CF}^{2} \\
(\mathrm{~cm})\end{array}$} & \multirow[b]{2}{*}{$\begin{array}{l}\mathrm{DF}^{2} \\
(\mathrm{~cm})\end{array}$} \\
\hline & Prod.total & In natura & $(0)$ & Indústria & (1) & & & \\
\hline $\mathrm{T} 1$ & $10,07 \mathrm{ab}$ & $5,15 \mathrm{ab}$ & 47,49a & $5,55 \mathrm{a}$ & $52,21 \mathrm{a}$ & $151,07 \mathrm{a}$ & $7,56 \mathrm{a}$ & $6,81 \mathrm{a}$ \\
\hline $\mathrm{T} 2$ & $12,82 \mathrm{a}$ & $5,60 \mathrm{a}$ & $43,30 \mathrm{a}$ & $7,22 \mathrm{a}$ & $56,72 \mathrm{a}$ & $129,90 \mathrm{a}$ & $7,47 \mathrm{a}$ & $6,82 \mathrm{a}$ \\
\hline $\mathrm{T} 3$ & $11,09 \mathrm{ab}$ & $4,75 \mathrm{ab}$ & $41,75 \mathrm{a}$ & $6,34 \mathrm{a}$ & $58,21 \mathrm{a}$ & $138,81 \mathrm{a}$ & $7,69 \mathrm{a}$ & $6,89 \mathrm{a}$ \\
\hline $\mathrm{T} 4$ & $8,87 \mathrm{~b}$ & $3,59 \mathrm{~b}$ & $40,32 \mathrm{a}$ & $5,29 \mathrm{a}$ & $59,68 \mathrm{a}$ & $132,08 \mathrm{a}$ & $7,61 \mathrm{a}$ & $6,83 \mathrm{a}$ \\
\hline T5 & $9,99 \mathrm{ab}$ & $4,12 \mathrm{ab}$ & $41,18 \mathrm{a}$ & $5,87 \mathrm{a}$ & $58,82 \mathrm{a}$ & $128,76 \mathrm{a}$ & $7,37 \mathrm{a}$ & $6,84 \mathrm{a}$ \\
\hline $\mathrm{T} 6$ & $9,87 \mathrm{ab}$ & $4,46 a b$ & $44,72 \mathrm{a}$ & $5,41 \mathrm{a}$ & $55,28 \mathrm{a}$ & $138,43 \mathrm{a}$ & $7,78 \mathrm{a}$ & $7,01 \mathrm{a}$ \\
\hline Teste F & * & * & n.s. & n.s. & n.s. & n.s. & n.s. & n.s. \\
\hline C.V.(\%) & 14,4 & 16,9 & 11,4 & 18,8 & 8,6 & 7,7 & 2,7 & 2,9 \\
\hline DMS (5\%) & 3,52 & 1,79 & 11,29 & 2,57 & 11,28 & 24,12 & 0,47 & 0,46 \\
\hline
\end{tabular}

Médias seguidas da mesma letra, na coluna, não diferem entre si, ao nível de 5\% de probabilidade, pelo teste de Tukey.

T1: milho (Zea mays L. - BR 106) como cultura intercalar; T2: feijão (Phaseolus vulgaris L. cultivar Pérola) como cultura intercalar; T3: feijão-de-porco nas entrelinhas e capina com enxada nas linhas; T4: feijão-de-porco nas entrelinhas e controle químico nas linhas; T5: planta daninha controlada quimicamente (em toda parcela); T6: testemunha (capina manual, sistema utilizada pelo produtor). ${ }^{\mathbf{P}} \mathbf{P M F}=$ Peso médio dos frutos; $\mathbf{C F}=$ Comprimento médio dos frutos; $\mathbf{D F}=$ Diâmetro médio dos frutos.

Para os caracteres físicos e químicos, observa-se que não houve diferenças significativas para acidez e sólidos solúveis totais entre os tratamentos. Por outro lado, o tratamento 5 (controle químico em área total) apresentou menor rendimento em suco $(28,75 \%)$, diferindo estatisticamente do tratamento 2 (feijão como cultivo intercalar) 39;75\%. Para relação sólidos solúveis totais/acidez, a maior relação $(5,41)$ foi obtida com o tratamento feijão como cultura intercalar, diferindo estatisticamente do tratamento 3 (cobertura do solo com feijão-de-porco) $(4,28)$ (Tabela 3).

TABELA 3 - Relação sólidos solúveis totais/acidez, rendimento em suco, acidez e sólidos solúveis totais no primeiro ano de produção de maracujazeiro-amarelo sob cultivos intercalares e controle de plantas invasoras. Cruz das Almas-BA, 1999-2000.

\begin{tabular}{ccccc}
\hline Tratamento & $\begin{array}{c}\text { Sólidos solúveis } \\
\text { totais/acidez }\end{array}$ & $\begin{array}{c}\text { Rendimento em suco } \\
(\%)\end{array}$ & $\begin{array}{c}\text { Acidez } \\
(\%)\end{array}$ & $\begin{array}{c}\text { Sólidos solúveis totais } \\
{ }^{\circ} \text { Brix }\end{array}$ \\
\hline T1 & $4,69 \mathrm{ab}$ & $32,50 \mathrm{ab}$ & $3,16 \mathrm{a}$ & $14,75 \mathrm{a}$ \\
$\mathrm{T} 2$ & $5,41 \mathrm{a}$ & $39,75 \mathrm{a}$ & $2,79 \mathrm{a}$ & $15,07 \mathrm{a}$ \\
T3 & $4,28 \mathrm{~b}$ & $33,00 \mathrm{ab}$ & $3,27 \mathrm{a}$ & $14,02 \mathrm{a}$ \\
T4 & $4,57 \mathrm{ab}$ & $34,25 \mathrm{ab}$ & $3,03 \mathrm{a}$ & $13,72 \mathrm{a}$ \\
T5 & $4,58 \mathrm{ab}$ & $28,75 \mathrm{~b}$ & $3,25 \mathrm{a}$ & $14,80 \mathrm{a}$ \\
T6 & $4,64 \mathrm{ab}$ & $34,00 \mathrm{ab}$ & $3,15 \mathrm{a}$ & $14,65 \mathrm{a}$ \\
\hline C.V. $(\%)$ & 9,8 & 14,9 & 7,7 & 4,8
\end{tabular}

Médias seguidas da mesma letra, na coluna, não diferem entre si, ao nível de 5\% de probabilidade, pelo teste de Tukey.
A relação benefício/custo mostrou que, para cada real investido na atividade, tem-se um retorno médio de $\mathrm{R} \$ 1,72$, considerando os tratamentos $1 ; 2 ; 3$ e 4 . O tratamento 5 é que apresentou o menor retorno médio $(\mathrm{R} \$ 1,49)$. O tratamento 6 apresentou um retorno médio de $\mathrm{R} \$ 1,82$. Concluiu-se então que:

a) Os herbicidas alachlor a 2,8 kg/ha + diuron a 1,2 kg/ha aplicados em pré-emergência com aplicação seqüenciada do herbicida glifosate a 1,5 kg/ha, em pós-emergência, foram seletivos para a cultura do maracujazeiro-amarelo no seu primeiro ano de cultivo.

b) O milho (Zea mays L. - BR 106) e o feijão (Phaseolus vulgaris L. cv. Pérola) podem ser recomendados como culturas intercalares no primeiro ano de cultivo do maracujá-amarelo.

c) $\mathrm{O}$ manejo da cobertura vegetal com utilização de herbicidas mostrou-se economicamente viável para o produtor.

\section{REFERÊNCIASBIBLIOGRÁFICAS}

BARBOSA, S. B. S. C. Avaliação econômica de métodos integrados de controle de ervas daninhas em abacaxizeiro. In: CONGRESSO BRASILEIRO DE FRUTICULTURA, 13, 1994, Salvador, BA. Resumos...Salvador, BA: 1994. p. 11.

COELHO, Y. S; SENA, M.G.C; OLIVEIRA, S.L. de. Sistemas diversificados de produção de citros no trópico semi-árido: uma alternativa para unidades familiares. In: CONGRESSO BRASILEIRO DE FRUTICULTURA, 13, 1994, Salvador, BA. Resumos...Salvador, BA: 1994. p. 349-350.

DURIGAN, J. C. Controle de plantas daninhas. In: RUGGIERO, C. (Ed.) Cultura do maracujazeiro. Ribeirão Preto: Legis Summa Ltda., 1987. p 67-75.

FRANS, R.E.; TALBERT, R.E. Design of field experimentes and the measurement and analysis of plant responses.In: TRUELOVE, B. ed. Research methods in weed science. Fayetheville, Arkansas: Southern weed Science Society, 1977.p.16-23.

LEIHNER, D.E. Yuca em cultivo asociado: manejo x evalución. Cali: CIAT, $1983.80 \mathrm{p}$.

LIMA, A. de. A.; CARVALHO, J. E. B.; CALDAS, R. C. Seletividade de herbicidas pré-emergentes em mudas de maracujá-amarelo. Revista Brasileira de Fruticultura, Cruz das Almas. v.21, n.3, p.379-381, 1999.

MAGALHÃES, A. F. de. J. Adubação verde na cultura do citros. In: CONGRESSO BRASILEIRODEFRUTICULTURA, 13, 1994, Salvador, BA. Resumos...Salvador-BA, 1994. p. 505-506.'

MATTOS, P. L. P. \& SOUZA, A. da. S. Mandioca (Manihot esculenta Crantz) consorciada com milho (Zea mays L.) no sistema de fileiras duplas . Revista Brasileira de Mandioca, Cruz das Almas, v.6, n.1, p.49-53, 1987.

PEREIRA, R. C. Imazipar, um novo herbicida para uso em plantações de seringueira Pesquisa Agropecuária Brasileira, Brasília. v.22, n.5, p.469-476, 1987.

SILVA, J. R. da. \& RABELO, J. M. L. Manejo cultural do maracujazeiroamarelo (Passiflora edulis Sims f. flavicarpa Deg.) na região do triângulo mineiro - Mg. In: A cultura do maracujá no Brasil. Jaboticabal, FUNEP, 1991, 247p.

UZEDA, J. V.; MAGALHÃES, A. F. de. J.; GOMES, J. C.; SOUZA, L. F. da. S. Maracujá (Passiflora edulis Sims). Manual de Adubação e calagem para o estado da Bahia. Salvador, BA: CEPLAC/EMBRAPA/ EPABA/NITROFÉRTIL, 1989.p. 139-140. 